\title{
A SUSPEITA DE ABUSO SEXUAL E O PSICANALISTA
}

Diante da solicitação crescente de avaliação e acompanhamento de casos de suspeita de abuso sexual contra crianças no âmbito das instituições de saúde, este artigo discute o desafio que se coloca ao psicanalista quando se encontra em posição de responder a tais demandas, considerando o discurso em que elas se apoiam. O tema implica, portanto, interrogar de antemão o discurso em jogo, o que leva à problematização da conjunção entre responsabilidade subjetiva e responsabilidade jurídica, assim como entre clínica e pericia, da relação entre saber e verdade e das concepcões da criança como objeto e sujeito.

Descritores: abuso sexual contra a criança; psicanálise; perícia; clínica; verdade.

\author{
Vinicius Anciães Darriba \\ Andréa Barbosa de Albuquerque
}

DOI: http//dx.doi.org/10.11606/issn. 1981-1624.v23i3p611-625.

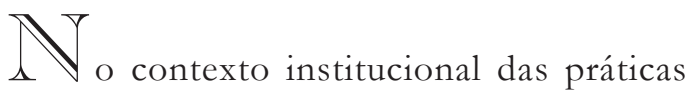
em saúde, constata-se atualmente uma crescente preocupação com identificação, notificação e intervenção em casos de abuso sexual contra crianças e adolescentes. Se a atenção concedida a essas situações vem aumentando já há algumas décadas (Amazarray \& Koller, 1998; Brasil, 2002; Brito, Zanetta, Mendonça, Barison \& Andrade, 2005; Minayo, 2006; Pfeiffer \& Salvagni, 2005; Polanczyk, Zavaschi, Benetti, Zenker \& Gammerman, 2003), é difícil não levá-la em conta ao considerarmos um eventual crescimento do número de casos registrados. Por outro lado, há autores (Birman, 2007; Calligaris, 2000; Figueira, 1986) que abordam

Professor adjunto do Instituto de Psicologia da Universidade do Estado do Rio de Janeiro, Rio de Janeiro, RJ, Brasil.

[Doutora em teoria psicanalítica pela Universidade Federal do Rio de Janeiro. Membro do Espaço Brasileiro de Estudos Psicanalíiticos. Psicóloga do Hospital Universitário Pedro Ernesto da Universidade do Estado do Rio de Janeiro, Rio de Janeiro, RJ, Brasil. 
mudanças na cultura que se traduziriam em um enfraquecimento do poder patriarcal, em certa homogeneização das faixas etárias, em uma fragilização das normas de separação entre as gerações e em uma erotização da imagem da criança, desde as quais se poderia pensar em um efetivo incremento dos casos.

Não trataremos aqui da questão relativa à fidedignidade de um suposto aumento do número de casos de abuso sexual contra crianças e adolescentes nem de suas possíveis causas. O ponto de que partimos é a inquestionável maior visibilidade que o tema assumiu, o que inclui as modalidades da dúvida e da suspeita como pontos de convergência para um olhar que passa a estar associado à ação do profissional de saúde. Trata-se de um olhar preponderante no contexto da vigilância cada vez mais estrita de que são incumbidos os agentes institucionais da área da saúde (como também os da educação, os da justiça, os da assistência social) no sentido da normatização dos modos de viver - relacionar-se, trabalhar, comer etc. - de indivíduos e famílias. A investigação da intimidade das famílias sendo justificada por um modelo biopsicossocial de saúde, o abuso sexual de crianças e adolescentes figura, de modo privilegiado, como mal a ser combatido.

Quando a isso se associa a presunção de que a quantidade de casos é expressiva, passa a se configurar urgente a capacitação dos profissionais de saúde para identificação e tratamento de tais situações. O problema é que, embora o conjunto destes profissionais componha um universo bastante heterogêneo no que diz respeito tanto ao fundamento epistêmico de suas formações quanto aos princípios éticos de sua atuação, a demanda que lhes é endereçada encontra-se referenciada de modo pregnante ao modelo positivista, que supõe a distinção clara entre sujeito e objeto e reporta a verdade ao domínio do que é objetivável (Albuquerque, 2012). Neste artigo, discutiremos o desafio posto por esse tipo de demanda, em casos de suspeita de abuso sexual tratados em âmbito institucional de saúde, quando o endereçamento é feito a quem alicerça sua prática na doutrina psicanalítica.

612 Estilos clin., São Paulo, v. 23, n. 3, set./dez. 2018, 611-625. 


\section{Crítica ao discurso da saúde}

Embora não pretendamos nos ater, na discussão, à dimensão mais evidente que consistiria em situar o caráter reducionista da demanda endereçada ao profissional psi em termos periciais - "houve ou não houve abuso?" -, não podemos deixar de interrogar o discurso em jogo, de modo a situarmos com relação a ele nossa prática, em suas coordenadas ética e política. Neste sentido, podemos observar, na consulta à literatura disponível sobre o tema, que certos elementos, por se repetirem, informam-nos de algo que faz parte da lógica que prevalece no tratamento da questão dentro do ambiente institucional. Vejamos alguns.

É comum que, para além das marcas que o exame físico pode identificar, certas outras marcas também sejam tomadas como efeitos dos quais o abuso sexual sofrido seria a causa. Pode-se ver isso com relação a: desatenção, dificuldades escolares, medo, ansiedade, conduta excessivamente sexualizada, masturbação frequente (Azevedo, 2001; Habigzang, Koller, Stroeher, Hatzenberger, Cunha \& Ramos, 2008; Pfeiffer \& Salvagni, 2005). No que se refere aos últimos exemplos, é inevitável nos vermos levados de volta a uma teoria da sedução, como a que Freud (1896/1980, 1925/1980, 1933/1980) cedo abandonou, segundo a qual a sexualidade na infância é necessariamente sintomática de uma iniciação precoce em decorrência de uma situação efetiva de abuso. Para além disso, contudo, podemos entrever ainda uma provável generalização a partir de casos particulares.

Se supomos não ser arbitrária a relação estabelecida, não estar ela baseada apenas no senso comum, possivelmente os sinais associados à ocorrência de abuso sexual foram detectados em casos particulares. Tratar-se-ia, então, de uma inferência que de uma situação estabelecida (no caso X, estabeleceu-se a associação entre a causa A e o efeito B) deduziria ou pelo menos formularia uma hipótese sobre a causa a partir da presença do efeito (no caso Y, a presença do efeito B colocaria a pergunta sobre a causa A). Dá-se uma simplificação que, se nutre uma esperança de desambiguação, é pouco afeita à realidade clínica em que as situações se desdobram. Finalmente, é preciso dizer que tal lógica não se encontra a priori vedada às conexões que, desde o senso comum, a moral sexual ou os ideais relativos às funções parentais, podem se infiltrar sob roupagem científica. Nesse sentido, vale lembrar o comentário de Calligaris (1999) de parecer haver um receio de que, se o abuso não for considerado patogênico, seja mais difícil considerá-lo errado.

Há uma tendência no discurso da saúde a equiparar responsabilidade jurídica e responsabilidade 
subjetiva (Piza \& Alberti, 2014). Não colocamos em questão a responsabilidade penal atribuída pelo sistema jurídico - e compartilhada socialmente - exclusivamente ao adulto na situação de abuso sexual. Mas importa-nos problematizar o lugar atribuído à criança na cena de abuso pelo discurso da saúde, na medida em que essa concepção orienta as abordagens clínicas da criança nesses serviços. Endossando a perspectiva jurídica, a criança tende a ser colocada no lugar de vítima passiva, sendo concebida como objeto da ação do outro - o agressor -, devendo ser objeto de proteção e cuidado por parte da rede de assistência. Nesse sentido, o profissional de saúde parte de uma configuração pré-estabelecida para sua abordagem da família, inferindo a priori o lugar ocupado pela criança na situação identificada como de abuso sexual (Brandão Junior \& Ramos, 2010). Se, aos olhos do profissional, a cena pode se apresentar plana, clara, pelo olhar da criança pode não ser bem assim. O sentido por ela conferido à cena é tributário de sua posição subjetiva, do modo como interpreta suas relações e suas vivências, sempre mediada pela fantasia, atravessada pelo desejo.

As possibilidades de sentido são inumeráveis, e é a escuta da criança que permitiria apreender como esse acontecimento se insere em sua história, em sua trama subjetiva. No entanto, ao se designar precocemente o lugar de cada um na cena de abuso, delimita-se também o que a criança pode dizer - e o que o profissional pode ouvir do que é dito. Nessa perspectiva, essa abordagem pode favorecer o silenciamento da criança, na medida em que lhe atribui de antemão um lugar na cena, afirma de antemão sua inocência: não foi sua culpa. O que se encontra de saída excluído é o sentido sempre singular atribuído pela criança à experiência vivida. Sua vitimização parece justificar-se pela imaturidade, que responderia por seu desconhecimento da sexualidade e pela impossibilidade de dizer não, de furtar-se ou fazer cessar as investidas sexuais do dito agressor.

O filme $A$ caça (Vinterberg, 2012) ilustra bem a complexa dinâmica que se estabelece, a partir do relato de uma investida sexual, entre a criança e os adultos que se responsabilizam por ela e buscam estabelecer a verdade objetiva do fato ocorrido. A partir do momento que se assume a veracidade factual, todo relato ou silêncio - dissonantes são apreendidos como indícios que, em sua própria distorção, confirmam o evento, por definição, traumático.

\section{A disjunção entre saber e verdade e o sexual}

O que se pode constatar quanto à demanda endereçada ao profissional psi é que ela supõe certa expertise sobre a sexualidade infantil, em contraposição ao embaraço que essa continua a exercer sobre o adulto, mesmo na posição de

614 Estilos clin., São Paulo, v. 23, n. 3, set./dez. 2018, 611-625. 
profissional de saúde. Além disso, apresenta-se, como já dissemos, infletida para o registro da perícia, em se tratando de uma temática em relação à qual os discursos médico, jurídico ou assistencial não transigem com a equivocidade. Busca-se saber a verdade em razão do dever de proteger a criança, verdade que também concerne à proteção do próprio profissional de saúde, sujeito a sanções pelo não cumprimento de seu dever. Ele também tem do que se proteger.

Além da inclinação positivista própria a contextos em que se pretende consolidar o estatuto científico da prática e da preocupação com o devido atendimento ao que é legalmente exigido do profissional, a vinculação da verdade ao objetivável, ao que se pode saber, responde ainda, no âmbito que examinamos, a um terceiro condicionante. $\mathrm{O}$ discurso que se consolidou entre especialistas no tema do abuso sexual (Furniss, 1993) é o de que o trauma, em sua dimensão patogênica, instaura-se junto à violência sofrida. Daí pode derivar tanto a associação do traumático ao fato objetivo quanto a da dimensão temporal, designada pelo pós-traumático, também à cronologia dos fatos. Deste modo, a incumbência principal do profissional psi seria a de realizar a perícia que permitisse confirmar a suspeita de abuso, a partir do que ele já saberia sobre aquela criança enquanto vítima. Caberia então acionar imediatamente o dispositivo terapêutico indicado para estes casos, já que se trataria de vítima de determinado tipo de trauma.

Da perícia à terapêutica, cabe questionar a que clínica estaríamos reduzidos. Certamente uma clínica ajustada a uma cultura do tudo visivel, como define Gérard Wajcman (2011). Se antes o que dominava era uma cultura do segredo, a crença agora é de que possa não haver ângulo morto, ponto cego. $\mathrm{O}$ desejo de ver que existe em cada um se encontra vetorizado pelo discurso da ciência para a ideia de que tudo pode ser visível, de que todo visível deve ser visto e de que toda verdade deve se confessar na visibilidade. A prospecção da verdade sobre o abuso sexual ou a captação de imagens pelas câmeras de segurança em nossas ruas não se justificam 
a princípio por um desejo de ver. Seriam ações necessárias à solução de problemas de justiça, de sociedade, de segurança, de saúde mental etc. O tudo ver da atualidade legitima-se em um tudo resolver, sendo o paradigma problema-solução, como designa Jean-Claude Milner (Miller \& Milner, 2004), um paradigma decisivo na determinação do moderno, segundo o autor. À medida que um problema é colocado no âmbito da sociedade, demanda-se ao político que encontre uma solução para ele - tal é a relação da sociedade com a política no universo moderno.

No que tange à identificação do problema do abuso sexual contra crianças e adolescentes, consolidou-se a ideia de que a solução passa por saber a verdade. Caso particular, ou talvez paradigmático, no qual a revelação da verdade condiciona a solução na esfera tanto criminal quanto da saúde mental. Em um primeiro tempo lógico, de perícia, a elucidação da verdade do crime e da verdade do trauma sobrepõem-se. A atestação do fato orienta, assim, a terapêutica de um corpo previamente autopsiado. Tratando-se, contudo, de uma vítima que está viva e - ainda que se a considere traumatizada - falante, é preciso considerar sua relação com a verdade. Como vimos até aqui, atribui-se valor à verdade que passa pela criança no sentido de ela possibilitar que um ato criminoso e uma situação traumática sejam identificados, em benefício da sociedade e da própria criança. Mas, junto a isso, que valor se poderia ponderar quanto à preservação da dimensão privada, íntima, inviolável de sua relação com a verdade? Se na base da busca pela justiça ou pela proteção da criança há um consenso quanto ao direito da inviolabilidade do corpo, não se poderia perguntar pelo direito a uma outra inviolabilidade a se afirmar nessa busca, a da relação entre sujeito e verdade?

Afinal, na cultura do tudo visivel, de que fala Wajcman (2011), há que cuidar para não duplicar (se havida) ou inaugurar (se não havida) a violência ao impor a transparência, ao extrair o íntimo à força, ao arrancar do sujeito sua verdade. Segundo o autor, é uma violência e uma ilusão, pois não está em jogo o ocultamento da verdade, mas a condição mesma do sujeito de não ser mestre desta verdade, de encontrar-se dividido (Wajcman, 2011). É este sujeito dividido que, por um lado, configura uma sombra que se pretenderia eliminar em um regime de plena visibilidade. Por outro lado, e aí voltamos a Milner (2011), é também ele, sua intimidade, o segredo de sua divisão, que não conta nos dispositivos estatísticos que constituem e validam as categorias que aqui, por exemplo, pretendem subsumir na integralidade a realidade da cena sexual entre adulto e criança.

Toda essa discussão é cara a quem se orienta pela psicanálise, particularmente àquele que se vê convocado a operar no terreno de que tratamos, na medida em que, se o discurso que prevalece passa a ser o da dissociação 
entre a verdade e a divisão do sujeito, para o psicanalista se configura o limite da impostura. Não por acaso, quanto ao que veio a fundar um discurso analítico, Lacan (1986, p. 31) insiste

no fato de que Freud avançava numa pesquisa que não é marcada pelo mesmo estilo que as outras pesquisas científicas. O seu domínio é o da verdade do sujeito. A pesquisa da verdade não é inteiramente redutível à pesquisa objetiva, e mesmo objetivante, do método científico comum. Trata-se da realização da verdade do sujeito, como de uma dimensão própria que deve ser destacada na sua originalidade em relação à noção mesma da realidade.

Mais do que apenas recolher as implicações da experiência analítica para o lugar da verdade, Lacan atesta, na sequência de seu ensino, que estas não são sem consequência sobre o que se toma como saber, em especial para sua relação com a verdade: "Existe um saber que diz: Há em algum lugar uma verdade que não se sabe, e é ela que se articula no nível do inconsciente. É aí que devemos encontrar a verdade sobre o saber" (Lacan, 2008, p. 195). O que a psicanálise, com Freud, veio a articular, sob a rubrica do inconsciente, de uma verdade que não se sabe deu, ao mesmo tempo, a verdade do saber decorrente da exploração desse campo. Verdade de difícil aceitação, pois não diz respeito à insuficiência ou ao inacabamento do saber, mas a uma impossibilidade estrutural de converter a verdade toda em saber. Cabe ressaltar, quanto ao tema que aqui exploramos, que isto se evidenciou a Freud justamente na tentativa de constituir um saber sobre o sexual.

Em "A história do movimento psicanalítico", encontramos a confissão de que Freud (1914/1980, p. 27) esteve a ponto de desistir do trabalho quando a hipótese da sedução infantil na histeria desmoronou, tendo perseverado apenas porque já não tinha outra escolha. Indicou ainda que, se tivesse desistido, teria reagido como Breuer, seu estimado antecessor, ao fazer sua descoberta indesejável - a significação da sexualidade na etiologia das neuroses. Não podemos dizer que Freud e Breuer tenham feito escolhas diferentes, já que Freud nos diz que o que diferencia sua posição é não ter tido escolha. Seguir em seu trabalho - o que, na situação específica, possibilitou que chegasse ao conceito de realidade psíquica - foi algo vivido por Freud, portanto, como uma imposição, que reporta à concepção de desejo que a psicanálise veio a consagrar.

Retomemos, contudo, o ponto-chave de que a hipótese que, ao se diluir, ameaçou a continuidade do trabalho de Freud dizia respeito ao sexual. E tomemos na perspectiva de que aquilo com que ele se deparou seja menos da ordem do erro de uma hipótese relativa ao lugar do sexual na etiologia da neurose e mais da evidência de que, ao tentar constituir um saber em torno do sexual, algo lhe escapou. A solução subsequente, com a inclusão da realidade psíquica neste 
domínio, tampouco conseguirá dizer tudo. O que Freud suportou, portanto, ao seguir com a psicanálise não foi o fracasso de uma hipótese, mas a impossibilidade de constituir um saber capaz de dizer tudo a propósito do sexual. No encaminhamento de sua hipótese etiológica, a busca de um trauma na origem o dirigiu ao sexual. $\mathrm{O}$ que isso evidenciou, em última instância, é que o sexual é traumático, podendo-se ler no sentido de que no campo do sexual nos deparamos com um limite à constituição de saber.

\section{Clínica e perícia: sujeito e objeto}

Sob determinado ângulo, é uma falsa controvérsia a que opõe a culpa do adulto à fantasia da criança, já que levaria a tomar o descarte da teoria da sedução como uma absolvição do adulto. $\mathrm{O}$ abuso concebido como algo que potencialmente traumatiza toda criança é uma produção discursiva do adulto dirigida à prevenção e ao tratamento. Quanto ao que efetivamente tenha traumatizado a criança, nada poderá vir a ser dito sem o recurso à fantasia. Este é um dos impasses clínicos em que se incorre ao equiparar a responsabilidade jurídica à responsabilidade subjetiva, pois, desde a perspectiva psicanalítica, seria a abertura à segunda, sem a submissão prévia à primeira, que poderia dirigir à dimensão do traumático em seu estatuto singular, de encontro contingente.

Sendo assim, o problema para aquele que propõe responder do lugar da psicanálise é que, quando se começa a escutar a criança ou o adulto, se institui o sujeito responsável em detrimento da verdade fatual de uma cena em que a criança ocupa um lugar de objeto que se encontra predeterminado. Ou seja, ao atender ao apelo, o analista já se priva do lugar desde o qual se poderia responder ao houve ou não houve abuso, o que não deve ser confundido com a supressão da responsabilidade jurídica. Trata-se antes de considerar que o locus da clínica e o da perícia podem não ser conjugáveis, e principalmente ousar tomar

618 Estilos clin., São Paulo, v. 23, n. 3, set./dez. 2018, 611-625. 
como não evidente a precedência do segundo sobre o primeiro.

Em seu comentário sobre a condenação de uma psiquiatra por um tribunal de Marselha, em dezembro de 2012, qualificada como o anúncio de uma nova relação entre justiça e psiquiatria, Éric Laurent (2013) aborda justamente a escolha não inocente de privilegiar a perícia contra a posição da profissional em sua prática clínica. Trata-se de um caso de passagem ao ato por um paciente cuja psiquiatra foi condenada com base em uma lei recente na França, relativa a consequências não intencionais de decisões tomadas por agentes do Estado (conhecida como Lei Fauchon, de julho de 2000). Diferente do que tradicionalmente se passava, os juízes apoiaram sua decisão na perícia que avaliou haver uma divergência entre a gravidade do caso e a conduta terapêutica; divergência que poderia, também segundo o parecer, ser evitada, não tivesse a equipe cuidadora se deixado contaminar pela falta de noção do paciente quanto à gravidade de seus atos. Ou seja, as alegações concernentes à imprevisibilidade da passagem ao ato - no caso, o assassinato do companheiro da avó pelo paciente esquizofrênico - desde a perspectiva de quem se posta no terreno clínico não pesaram em comparação à avaliação do perito.

Sem entrar nos meandros do debate jurídico, o ponto assinalado por Laurent, e que concerne à discussão aqui proposta, refere-se à evidência de que, no domínio da perícia, torna-se concebível a previsibilidade da passagem ao ato até o limite em que o risco se encontre associado apenas ao mau exercício profissional ou à escolha da conduta terapêutica. A própria prática clínica se veria objetivada desde a perspectiva da perícia, o que no caso comentado por Laurent, e no tema por nós abordado, atende a um ideal de segurança cada vez mais presente na sociedade, a uma efetiva ideologia da prevenção do risco, na qual o que é da ordem do singular, da contingência, do imprevisto - e que diríamos próprio à experiência clínica, em particular sob a ótica da psicanálise - pode passar a se confundir com (im)perícia, irresponsabilidade. O ideal de segurança se veria alçado ao patamar de uma clínica segura, aquela circunscrita ao âmbito da normatividade administrativa, protocolar por definição.

Milner (2011) indica que o clínico não pode ser tomado por perito na medida em que este último trabalha tendo por horizonte a objetivação, no limite a certeza. Neste sentido, o ato paradigmático para a perícia não seria, segundo ele, o tratamento, mas a autópsia. Não passa despercebido ao autor que a intitulada medicina baseada em evidência - regra de ouro cuja abrangência só se amplia, desde o final do século passado, no âmbito da formação científica dos profissionais que atuarão no contexto clínico conjuga em seu léxico o que é próprio tanto à racionalidade científica quanto 
à investigação policial. É então curioso que tenha sido ao interrogar os desenvolvimentos da criminologia, em 1950, que encontramos indicações de Lacan (1950/2003) que apontam em sentido contrário: “que os melhores espíritos não se sintam tentados, sob a denominação de criminologia, pelo sonho de um tratamento inteiramente objetivo do fenômeno criminal" (p. 129); "a denúncia do Universo mórbido do crime não pode ter por corolário nem por finalidade o ideal de uma adaptação do sujeito a uma realidade sem conflitos" (p. 128).

Tal posicionamento é consequente ao que deriva da experiência analítica, segundo Lacan. Alcança, contudo, em seu entendimento, o que estaria em jogo também na ação médica:

a verdade a que a psicanálise pode conduzir o criminoso não pode ser desvinculada da base da experiência que a constitui, e essa base é a mesma que define o caráter sagrado da ação médica - ou seja, o respeito pelo sofrimento do homem. (Lacan, 1950/2003, p. 131)

Nesta passagem, é não apenas a ação do analista, mas também a do médico que se vê limitada pelo ideal de uma adaptação do sujeito a uma realidade sem conflitos. Voltando a Milner (2011), comenta que, ainda mais do que manter a distância entre a psicanálise e a medicina, Lacan estava a preservá-las ambas da injunção que lhes era endereçada, em nome da prevenção e da repressão do crime. O respeito ao sofrimento figuraria, nestes termos, como uma borda a fazer obstáculo a tal injunção objetivante.

Se é obstáculo à objetivação - no caso da discussão de Lacan, do fenômeno criminal -, o sofrimento enquanto borda aponta para o que não cabe de todo nos requisitos de evidência, nos protocolos generalizantes, nos procedimentos avaliativos de cunho administrativo. Por seu lado, a primazia da evidência, do protocolo, da avaliação, da perícia sobre a clínica, em síntese, escolhe a via contrária. Segundo Milner (2011), seguindo a mesma lógica de que o sofrimento é esta borda que faz obstáculo à objetivação, não se trata de indiferença a ele, mas da condição de que ele não subsista fora de parâmetros objetivos, ou seja, de que ele não dê abrigo ao que é singular, ao que não encontra equivalente. Nos casos de suspeita de abuso sexual, em que a esfera clínica é sombreada pela criminal, encontramo-nos em um terreno onde tais questões avultam.

A perícia seria, assim, a objetivação consumada. E ela pode ou não se estabelecer como modelo para a clínica; a depender, seguindo Lacan, do respeito pelo sofrimento do homem, o que se toma aqui justamente pelo que há de singular e que constitui, portanto, uma margem que faz obstáculo à objetivação. Célio Garcia (2004), em um artigo sobre a noção de vítima no discurso da época, distingue o sujeito da vítima, tomando o primeiro justamente no sentido que reporta à singularidade, ao acontecimento, ao passo que a vítima se inscreve na lógica do 
direito - dos direitos humanos, das crianças, dos consumidores etc., isto é, de uma identidade coletiva e não contingente. Para além de uma incontornável perspectiva cidadã apoiada no aspecto jurídico-formal, a interrogação que o autor sustenta, e que reverbera para nossa questão clínica, diz respeito ao desafio de encontrar, na vigência de um discurso que alinha in totum o estatuto da vítima ao de alguém a ser protegido (proteger a vítima) e cuidado (cuidar da vítima), as brechas para a legitimação deste sujeito de que se trata, a se efetivar na assunção mesma do acontecimento traumático.

Um último ponto a ser abordado retoma a inquirição se houve ou não houve abuso, na medida em que ela implica a ideia de uma realidade a ser conhecida. Se já vimos, antes, ter Lacan (1986) indicado que o domínio da pesquisa de Freud é o da verdade do sujeito, e que essa deve ser destacada em sua originalidade com relação à noção de realidade, cabe agora adentrar o que resulta de subversão, nesta mesma via, também com respeito à noção de conhecimento. A relação da verdade com o sujeito não implica, como desenvolvemos, a transparência deste último, mas reitera sua divisão. Por sua vez, o objeto que Lacan conceitua em articulação a este sujeito que se distingue por se encontrar estruturalmente dividido objeto $a$ - entra em cena como um objeto cujo estatuto não é o de objeto do conhecimento. Mais do que isso, Lacan (2009, p. 49) entende que, no âmbito do que se desdobra do discurso analítico, como aqui, "essa coisa com que se sonhara no passado, e que era chamada de conhecimento", já se encontra subvertida.

Se definimos o analista como efeito desse discurso, trata-se para ele do objeto $a$ e do sujeito dividido, com o que a relação entre objeto do conhecimento e sujeito do conhecimento já se encontra subvertida. No momento em que a função analista opera, não cabe mais, portanto, a pretensão de se assentar em tal relação. A metáfora subjacente ao conhecimento, segundo Lacan (2012, p. 38), supõe a bipolaridade, do ativo e do passivo, diante da qual a psicanálise revela "o desvio, a barreira, a chicana, o desfilamento da castração". Não há como dissociar a 
operação pela qual se aposta em fazer da vítima sujeito, mirando além de um objeto a ser conhecido, para ser protegido e cuidado, daquela em que, "para que exista uma chance de analista" (Lacan, 1971-1972/2011, p. 63), outro objeto, o objeto $a$ desta feita, deve ocupar seu lugar no discurso.

A definição rigorosa do lugar do analista priva-o, como vimos, no que concerne à sua prática, na qual se dirige a um sujeito dividido, de responder a uma questão objetiva de um lugar de saber. Quando integra uma equipe multidisciplinar, no entanto, diante da demanda para averiguar se houve ou não abuso, ele se vê diante do desafio de atuar em duas vertentes que, se não se opõem, não podem tampouco ser assimiladas. No que se refere à criança, cabe a ele sustentar uma prática que não configura uma variante, uma aplicação ou uma adaptação do dispositivo posto em ação pela presença do analista, apesar do cenário de tal atendimento. Já junto à equipe, trata-se de intervir no âmbito das discussões dos casos não respondendo como esperado às suas inquietações, mas apostando em favorecer, por meio do esforço de transmissão do que a experiência analítica pôs em jogo, a construção de outras perspectivas de apreensão da situação em questão que não se resumam ao enquadramento de vítimas e culpados.

THE SUSPICION OF CHILD SEXUAL ABUSE AND THE PSYCHOANALYST

\section{Abstract}

Faced with the increasing demand for evaluation and treatment of cases of suspected child sexual abuse in health institutions, this article discusses the challenge facing the psychoanalyst when he is in position to respond to such demands, considering the discourse they are based on. The theme implies, therefore, asking this discourse in advance, which leads to questioning the conjunction of subjective between responsibility and legal liability, as well as between clinical practice and expert testimony, of issues concerning the relationship between knowledge and truth and of the approach of the child as object and subject.

Index terms: child sexual abuse; psychoanalysis; legal expertise; treatment; truth.

\section{LA SOSPECHA DE ABUSO SEXUAL Y EL PSICOANALISTA}

\section{RESUMEN}

Ante la creciente solicitación de evaluación y seguimiento de casos de sospecha de abuso sexual de niños en el ámbito de las instituciones de salud, el presente articulo discute el desafio que se plantea al psicoanalista, cuando es él quien se encuentra en posición de responder a tales demandas, considerando el discurso sobre el cual se apoyan. El tema implica, por lo tanto, interrogar de antemano el discurso en juego, lo que lleva a la problematización de la conjunción entre la responsabilidad subjetiva y la responsabilidad jurídica, así como entre la clinica y la pericia, de la relación entre el saber y la verdad $y$ de las concepciones del niño como objeto y sujeto.

Palabras clave: abuso sexual contra niños; psicoanálisis; pericia; clínica; verdad. 


\section{REFERÊNCIAS}

Albuquerque, A. (2012). Violências em família. In M. I. C. Moreira, \& S. D. M. S. Carellos (Orgs.), Familias em vulnerabilidade social: é possivel auxiliar sem invadir? (pp. 103-115). Curitiba, PR: Editora CRV.

Amazarray, M. R., \& Koller, S. H. (1998). Alguns aspectos observados no desenvolvimento de crianças vítimas de abuso sexual. Psicologia: Reflexão e Crítica, 11(3), 559-578. doi: 10.1590/ S0102-79721998000300014

Azevedo, E. C. (2001). Atendimento psicanalítico a crianças e adolescentes vítimas de abuso sexual. Psicologia, Ciência e Profissão, 21(4), 66-77. doi: 10.1590/S1414-98932001000400008

Birman, J. (2007). Laços e desenlaces na contemporaneidade. Jornal de Psicanálise, 40(42), 47-62.

Brandão Junior, P. M. C., \& Ramos, P. L. (2010). Abuso sexual: do que se trata? Contribuições da psicanálise à escuta do sujeito. Psicologia Clínica, 22(1), 71-84. doi: 10.1590/S0103-56652010000100005

Brasil, Ministério da Saúde (2002). Violência intrafamiliar: orientaçôes para a prática em serviço. Brasília, DF: Ministério da Saúde.

Brito, A. M., Zanetta, D. M. T., Mendonça, R. C. V., Barison, S. Z. P., \& Andrade, V. A. G. (2005). Violência doméstica contra crianças e adolescentes: estudo de um programa de intervenção. Ciência e Saúde Coletiva, 10(1), 143-149. doi: 10.1590/S1413-81232005000100021

Calligaris, C. (1999). A moral e o abuso sexual infantil. Pulsional: Revista de Psicanálise, 127, 80-81.

Calligaris, C. (2000). A adolescência. São Paulo, SP: Publifolha.

Figueira, S. (1986). O "moderno" e o "arcaico" na nova família brasileira: notas sobre a dimensão invisível da mudança social. In S. Figueira (Org.), Uma nova família? O moderno e o arcaico na família de classe média brasileira (pp. 11-30). Rio de Janeiro, RJ: Jorge Zahar.

Freud, S. (1980). Novos comentários sobre as neuropsicoses de defesa. In S. Freud, Edição standard brasileira das obras psicológicas completas de Sigmund Freud (J. Salomão, trad., Vol. 3, pp. 187211). Rio de Janeiro, RJ: Imago. (Trabalho original publicado em 1896)

Freud, S. (1980). A história do movimento psicanalítico. In S. Freud, Edição standard brasileira das obras psicológicas completas de Sigmund Freud (J. Salomão, trad., Vol. 14, pp. 16-82). Rio de Janeiro, RJ: Imago. (Trabalho original publicado em 1914)

Freud, S. (1980). Um estudo autobiográfico. In S. Freud, Edição standard brasileira das obras psicológicas completas de Sigmund Freud (J. Salomão, trad., Vol. 20, pp. 17-92). Rio de Janeiro, RJ: Imago. (Trabalho original publicado em 1925)

Freud, S. (1980). Novas conferências introdutórias: conferência 33. In S. Freud, Edição standard brasileira das obras psicológicas completas de Sigmund Freud (J. Salomão, trad., Vol. 22, pp. 139-166). Rio de Janeiro, RJ: Imago. (Trabalho original publicado em 1933)

Furniss, T. (1993). Abuso sexual da criança: uma abordagem multidisciplinar (M. A. V. Veronese, trad.). Porto Alegre, RS: Artes Médicas. 
Garcia, C. (2004). La víctima, su vez, su voz. Virtualia: Revista Digital de la Escuela de la Orientación Lacaniana, 12, 2-8.

Habigzang, L., Koller, S. H., Stroeher, F. H., Hatzenberger, R., Cunha, R. C., \& Ramos, M. S. (2008). Entrevista clínica com crianças e adolescentes vítimas de abuso sexual. Estudos de Psicologia, 13(3), 285-292. doi: 10.1590/S1413-294X2008000300011

Lacan, J. (1986). O seminário, livro 1: os escritos técnicos de Freud, 1953-1954 (B. Milan, trad.). Rio de Janeiro, RJ: Jorge Zahar.

Lacan, J. (2003). Premissas a todo desenvolvimento possível da criminologia. In J. Lacan, Outros escritos (V. Ribeiro, trad., pp. 127-131). Rio de Janeiro, RJ: Jorge Zahar. (Trabalho original publicado em 1950)

Lacan, J. (2008). O seminário, livro 16: de um Outro ao outro, 19681969 (V. Ribeiro, trad.). Rio de Janeiro, RJ: Jorge Zahar.

Lacan, J. (2009). O seminário, livro 18: de um discurso que não fosse semblante, 1971 (V. Ribeiro, trad.). Rio de Janeiro, RJ: Jorge Zahar.

Lacan, J. (2011). Estou falando com as paredes: conversas na capela de Sainte-Anne (V. Ribeiro, trad.). Rio de Janeiro, RJ: Jorge Zahar. (Trabalho original publicado em 1971-1972).

Lacan, J. (2012). O seminário, livro 19: ... ou pior, 1971-1972 (V. Ribeiro, trad.). Rio de Janeiro, RJ: Jorge Zahar.

Laurent, E. (2013). La fabrique de "l'individu dangereux". Lacan Quotidien, (265). Recuperado de https://bit.ly/2T3y3e5

Miller, J.-A., \& Milner J.-C. (2004). Voulez-vous être évalué? Paris: Bernard Grasset.

Milner J.-C. (2011). La politique des choses : court traité politique I. Paris: Verdier.

Minayo, M. C. S. (2006). A inclusão da violência na agenda da saúde: trajetória histórica. Ciência e Saúde Coletiva, 11(2), 1259-1267. doi: 10.1590/S1413-81232006000500015

Pfeiffer, L., \& Salvagni, E. P. (2005). Visão atual do abuso sexual na infância e na adolescência. Jornal de Pediatria, 81(sup. 5), S197-S204. doi: 10.1590/S0021-75572005000700010

Piza, L., \& Alberti, S. (2014). A criança como sujeito e como objeto entre duas formas de investigação do abuso sexual. Psicologia Clínica, 26(2), 63-85.

Polanczyk, G. V., Zavaschi, M. L., Benetti, S., Zenker, R., \& Gammerman, P. W. (2003). Violência sexual e sua prevalência em adolescentes de Porto Alegre, Brasil. Revista de Saúde Pública, 37(1), 8-14. doi: 10.1590/S0034-89102003000100004

624 Estilos clin., São Paulo, v. 23, n. 3, set./dez. 2018, 611-625. 
Reichenheim, M., Hasselman, M. H., \& Moraes, C. (1999). Consequências da violência familiar na saúde da criança e do adolescente: contribuiçôes para a elaboração de propostas de ação. Ciência e Saúde Coletiva, 4(1), 109-121. doi: /10.1590/ S1413-81231999000100009

Vinterberg, T. (Diretor). (2012). A caça [filme]. Dinamarca: Zentropa. Wajcman, G. (2011). El ojo absoluto (I. M. Agoff, trad.). Buenos Aires: Manantial.

viniciusdarriba@gmail.com Rua São Francisco Xavier, 524/10.005 - Bloco D 20550-011 - Rio de Janeiro - RJ - Brasil.

andreabalbuquerque@yahoo.com.br Travessa Euricles de Matos, 28 22240-010 - Rio de Janeiro - RJ - Brasil. 